of experimental methods to cytology, both to solve problems that are of immediate eytological interest and to produce results of practical importance in breeding. The different kinds of upset induced in cell-division are of interest in both ways. The diplochromosomes produced by Barber's heat treatment represent the mode of action of colchicine described by several workers in giving rise to polyploids. The third trend was the increasing linkage of Drosophila genetics with a minute study of salivary chromosomes, so that we found leading geneticists in America and England, like Demerec and Muller, offering papers embodying accounts of the breakage and reunion of chromosomes related to the direct observations of cytological workers like Kaufmann and Bauer.

This last development showed its widest bearings in the kind of population study described by Dobzhansky. The interlocking action of gene change and chromosome change now discovered in field genetics is evidently making it possible to bring the scheme of variation in Drosophila into the closest relationship with plant cytology. It gives the whole body of genetics and cytology a unity which is enabling them to be used as a joint tool of evolutionary research.

A word should be said of the technical side of cytology. The great advances of recent years were represented by an extensive microscope demonstration of chromosomes of Drosophila, Zea, Osmunda, Paris, Trillium, of various Orthoptera, and of Mammalia including man. A show of photomicrographic lantern slides brought home these exhibits to a larger audience and made it possible to compare the merits of different new methods of treatment.

A combined gene and chromosome session opened by Dr. W. T. Astbury was devoted to protein and virus studies in relation to the gene. It showed the results of applying new technical methods in protein and virus chemistry. It also showed that these, combined with the study of $\mathrm{X}$-ray mutations on the genetical side and the use of ultra-violet photography and microchemical tcsts on the cytological side are producing a practical convergence of biology and the physical sciences, a convergence that will probably mark the beginning of a new epoch.

\title{
PHYSIOLOGICAL GENETICS
}

\section{By Dr. C. H. WAdDINGTON}

$\mathrm{O}$ $\mathrm{NE}$ of the most active branches of genetics at the present time is the study of the ways in which genes affect developmental processes, and the section devoted to physiological genetics had a full and interesting programme. The problem of genic action is so complex and many sided that very many difierent methods of approach are possible, and examples of most of these can be found in the papers presented at the Congress.

The embryological approach was well exemplified in a paper by Landauer, in which he reviewed the correlated effects on different organs which are found both in fortuitous teratological specimens and also in abnormalities which are known to be dependent on genes. He suggested that many of these phenomena can be explained by the hypothesis of a general deleterious effect, often on the growth-rate, acting at a period which is critical for a certain set of developmental processes. A general embryological approach of a rather different kind was presented by Waddington, who discussed the relation of genes to developmental processes of the kind exemplified by the organizer reaction.

The importance of nuclear factors in particular steps of differentiation was analysed in more detail by Baltzer, who gave a summary of his. well-known and important work on bastard merogons, in which an enucleated egg of one species of newt is fertilized by a sperm of a different species. He showed that some tissues are able to develop to late embryonic stages, while others die presumably owing to disharmonies of nucleus and cytoplasm during particular processes of differentiation; still other tissues, such as some of the anterior mesoderm, while able to live, lose their normal power of inducing other organs-in this instance the balancers and gills. Similar studies of the importance of particular elements in the nucleus were reported by Poulson in his studies of the abnormalities produced by total absence of 
certain genes (homozygous deficiencies) on the early development of Drosophila.

Several reports dealt with gene effects on pro. cesses which are chemically more or less defined. Thus we had further chapters in the important and rapidly developing researches of Price, Lawrence and others on flower pigments, and Beadle, Ephrussi and others on Drosophila eye colours. Perhaps the most important new contribution in this field was a fresh study by Sewall Wright of guinea pig coat colours, which he dealt with in a preliminary way many years ago. He was now able to suggest a scheme for the relations of the numerous genes which are known, and to present a mathematical theory of their quanti. tative interactions.

Quite a different method of approach to the same problem was reported by Schultz and Caspersson, who, by studying the chromosome itself, obtained data which allow of some speculation as to the chemical changes occurring under the immediate influence of genes. Owing to their strong absorption in the middle ultra-violet, the distribution and changes of the substances belonging to the nucleotide group can be followed in the living cell by spectrophotometric methods elaborated by Caspersson. It is found that in the nucleus the nucleic acids seem to be indispensable for the development of chromosomes, and that they are synthesized mainly in earliest prophase just before the chromosomes split. Schultz studied translocations of parts of the heterochromatic regions of the chromosomes, which are rich in nucleic acid, into normal euchromatic regions in Drosophila. In certain of these translocations the adult flies show variegation for characters affected by genes near the position of the break in the chromosome, as though frequent mutations of the genes had occurred in late stages of development. Schultz showed that this variegation is correlated with cytological effects in the salivary chromo. some bands corresponding to the variegated genes; these effects ranged from appearance of excess nucleic acid to the assumption of a heterochromatic character and finally apparent dis. appearance. It is suggested that the appearance of excess nucleic acid is correlated with an inactivation of the gene as a developmental agent. The nucleic acid metabolism can be followed somewhat further, since it is found that the presence of extra heterochromatic material (for example, supernumerary $Y$-chromosomes) affects both the degree of variegation, the cytological correlates of variegation mentioned above, and also the nucleic acid content of the cytoplasm. The different types of nucleic acid occurring in chromosomes, nucleolus and cytoplasm can be determined spectroscopically and suggestions made as to their functional relations with the fundamental processes of gene action and gene reduplication.

It is possible, as Schultz suggests, that we may in this way obtain some insight into the changes of gene activity in different chromosome regions in the different tissues, which may provide a mechanism for the primary differentiation of the nuclei in development.

\title{
ANIMAL BREEDING IN THE LIGHT OF GENETICS
}

\author{
By DR. J. E. Nichols
}

$\mathrm{T}$ HE opening session was devoted to general considerations of animal genetics. H. C. McPhee described the United States Department of Agriculture's long-term inbreeding projects with pigs, sheep, and poultry, and the emphasis now being laid upon measuring the more complex physiological characters; and in reviewing the work at Wiad, Sweden, G. Bonnier mentioned the economy in numbers of experimental animals made possible by the use of monozygotic twins, and the similarity to plant breeding techniques now being obtained with poultry, where the mixed sperm from many males can be used in artificial insemination. W. K. Hirschfeld and G. M. van der Plank struck notes for many succceding speakers in directing attention to the distinction between frugal and less frugal breeds and families relative to production, and to the need of precise studies on differential demands upon the components of a ration. Their advocacy of the progeny test was pressed further by A. I. Hagedoorn, who suggests restricting to élite 